\title{
BELEIDSELEMENTEN IN EEN \\ DYNAMISCHE FINANCIERINGSTHEORIE
}

\author{
door Prof. Dr. C.F. Scheffer
}

\section{Inleiding}

"Beleidselementen in een dynamische financieringstheorie" is de titel van het proefschrift, waarop Dr. A. Th. de Lange op 5 juli 1957 aan de Universiteit van Amsterdam promoveerde tot doctor in de economische wetenschappen en dat onlangs is verschenen als deel XXVII in de reeks Bedrijfseconomische Monographieën.

Dr. de Lange heeft, naar onze mening, met dit werk een bijdrage geleverd tot verheldering van het inzicht in het financieringsvraagstuk en tot de ontwikkeling van de financieringstheorie. Er dient in dit tijdschrift daarom ruimer aandacht aan te worden besteed dan in het kader van een normale boekbespreking gebruikelijk is.

In het onderhavige artikel zullen echter toch niet alle details van de Lange's boek tot zijn recht kunnen komen, hoezeer zij dit overigens ook zouden verdienen. Zijn doorwrochte studie is in sommige opzichten $\mathrm{nl}$. zo gedetailleerd, dat wanneer alle waardevolle opmerkingen besproken zouden worden, daarvoor ongeveer even veel bladzijden nodig zouden zijn als het boek zelf bevat.

Wij hebben gemeend ons te moeten beperken tot de weergave van de kern van het boek en daarbij enkele aantekeningen te moeten plaatsen. Dit bleek echter geen gemakkelijke opgave te zijn. De kern van het boek is nl. nergens ,"kernachtig" weergegeven. Wanneer men zich b.v. na eerste lezing afvraagt: „Hoe luidt nu de Lange's dynamische financieringstheorie", dan zal men het antwoord schuldig moeten blijven, want dit staat met zoveel woorden niet in het boek. Door allerlei detailopmerkingen en door de betoogtrant, die niet uitmunt door klaarheid, is de kern min of meer gecamoufleerd.

Als wij het goed zien, is de kwintessens gelegen:

a. in de wijze van benadering van het financieringsvraagstuk en de nadruk. welke daarbij gelegd wordt op het voorlopige karakter, dat aan elke financieringsmethode moet worden toegekend;

b. in de introductie van het tijdselement in de financieringstheorie en de daarmee samenhangende betekenis, welke aan het beleid moet worden toegekend.

Op deze punten wordt in het onderstaande sub. 2 en 3 nader ingegaan. In de toepassing van de Lange's opvattingen m.b.t. het vraagstuk van de behoefte aan permanente financieringsmiddelen en de voorziening daarin komen de bovenbedoelde elementen opnieuw naar voren. Dit zullen wij sub. 4 trachten te demonstreren.

\section{De benadering van het financieringsuraagstuk}

Het financieringsvraagstuk dankt - aldus de Lange - zijn ontstaan ,enerzijds aan de volgtijdelijke veranderingen in de omvang van de vermogensbehoefte, anderzijds aan de verscheidenheid in de wijzen, waarop het vermogen ter beschikking wordt gesteld" (blz. 5). De gegeven grootheden of data van het financieringsvraagstuk hebben ten dele betrekking op de vermogensbehoefte en ten dele op de vermogensbeschikbaarheid. Als ge- 
vraagde grootheden kunnen worden aangeduid de tijdstippen, waarop en de hoeveelheden, waarin het vermogen op elke deelmarkt van de vermogensmarkt moet worden aangetrokken en eventueel teruggegeven, alsmede de bedragen waartoe en de tijdvakken waarin het bedrijf de opgetreden vermogensvermeerderingen niet tot uitkering moet brengen (blz. 9).

De waarden van de data zijn voortdurend aan veranderingen onderhevig, omdat $z$ ij zelf de resultanten $z$ ijn van een aantal aan veranderingen onderhevige krachten, welke enerzijds de structuur van de maatschappelijke produktie, de organisatie van het bedrijf, de voorraadpolitiek, de kredietpolitiek enz. beheersen en anderzijds bepalend zijn voor de structuur van de vermogensmarkt. De veranderingen in de datumwaarden zijn niet voorzienbaar. Dit houdt niet in, dat omtrent de datumwaarden niets bekend zou zijn; de onvoorzienhaarheid ligt in de onbekendheid met de intensiteit van bovenbedoelde krachten (blz. 13). In verband hiermede dient het financieringsvraagstuk steeds onder dynamische verhoudingen te worden gesteld. De veronderstelling van statische verhoudingen - bekendheid met de aard en intensiteit van de krachten, welke de waarden der data bepalen - zou tot oplossingen leiden, welke voor de werkelijkheid geen betekenis hebben.

Uit de onvoorzienbaarheid van de datumwaarden volgt, dat hieromtrent slechts bepaalde verwachtingen kunnen worden gekoesterd, welke gebaseerd zijn op een bepaald inzicht van de bedrijfsleiding in de ontwikkeling daarvan. Een definitieve oplossing van het financieringsvraagstuk - voor de gehele bestaansduur van de onderneming, welke zelf onvoorzienbaar is - zal nimmer kunnen worden gegeven. Men dient het probleem steeds in de tijd te zien en elke financieringsmethode draagt een voorlopig karakter; zij geldt slechts voor de tijd dat de data geen onverwachte veranderingen ondergaan.

In de laatste regels is een van de voornaamste stellingen van de Lange neergelegd nl. dat het financieringsprobleem dient te worden gesteld voor de gehele bestaansduur van de onderneming. Daarmede is tevens het onzekerheidselement - dat de definitieve oplossing van het financieringsvraagstuk uitsluit - geïntroduceerd en centraal gesteld. Men kan hoogstens komen tot een voorlopige oplossing, welke geldt zolang er geen onverwachte veranderingen in de data optreden. Deze benaderingswijze wekt de indruk van originaliteit, in het bijzonder door de aan de kwantitatieve beschouwingswijze ontleende terminologie. Op de keper beschouwd biedt zij o.i. echter weinig nieuws.

Het centraal stellen van het onzekerheidselement in de leer van de financiering is op zich geen novum. Aan J. L. Mey komt ten onzent de eer toe, dit als eerste te hebben gedaan en Diepenhorst heeft hem hierin trouw nagevolgd. Ook van Ravenstijn heeft zich veel moeite getroost om de dynamische omstandigheden en de onzekerheid in de leer van de financiering in het middelpunt van de belangstelling te plaatsen. Daar de Lange op deze weg wil voortgaan, doet het enigszins vreemd aan, dat zijn kritiek zich in hoofdzaak richt op voren genoemde schrijvers.

Dat er gedurende de gehele bestaansduur van de onderneming overeenstemming dient te bestaan tussen de uit de totale kapitaalsgrootte voortvloeiende vermogensbehoefte en de in het bedrijf beschikbare hoeveelheden vermogen zal o.i. door niemand worden ontkend, ook al wordt dit niet uitdrukkelijk gesteld. De Lange is van mening, dat Limperg en zijn leerlingen .,een belangrijk nieuw element in de problematiek van de financiering" hebben gebracht door het probleem te stellen voor de bestaansduur van het bedrijf en daarmede het tijdvak, waarop het financieringsprobleem betrek- 
king heeft, uitdrukkelijk hebben aangegeven (blz. 26). J. L. Mey heeft, volgens hem, in de ontwikkeling van de financieringstheorie weer een belangrijke stap achteruit gedaan door de probleemstelling noch te betrekken op de bestaansduur van het bedrijf, noch op de periode waarin de aard en de intensiteit van de krachten, welke in de beschouwingen worden betrokken kunnen worden overzien en in dit verband bekritiseert hij J. L. Mey's conceptie van de partiële financiering. Indien men vraagt, aldus de Lange ,naar de aanpassing van het op te nemen vermogen aan de omlooptijd van het vermogen in bepaalde kapitaalgoederen" (a la Polak) "heeft men het probleem reeds beperkt tot de tijdspanne, waarin die omloop zich afspeelt" en dit vindt in zijn ogen geen genade. "Van onvoorzienbaarheid van gebeurtenissen is hier geen sprake”. „Partiële financiering en dynamische verhoudingen kunnen elkaar (dan ook) niet verdragen" (blz. 34).

Deze kritiek op J. L. Mey achten wij niet gerechtvaardigd. Zeker, laatstgenoemde heeft het tijdvak, waarvoor hij het probleem stelde niet genoemd. Wij weten echter hoezeer hij in zijn proefschrift en leerboek aandacht besteed heeft aan het verloop van de totale vermogensbehoefte in de onderneming en het diversiteitsverschijnsel. Het spreekt o.i. vanzelf, dat hij evenmin als de Lange in staat is het verloop van deze totale vermogensbehoefte voor de gehele bestaansduur van het bedrijf te overzien en dat hij zich dus - evenals de Lange - moet beperken tot een periode, gedurende welke bepaalde verwachtingen worden gekoesterd omtrent de determinanten daarvan. Dat er volgens J. L. Mey ook onder dynamische verhoudingen omstandigheden kunnen zijn, waaronder de toepassing van partiële financiering naast de totale voor de onderneming gewenst kan zijn, behoeft o.i. geenszins te betekenen, dat men dan slechts transacties financiert zonder zich rekenschap te geven van de totale financieringsbehoefte en de voorziening daarin gedurende een overzienbare periode. Indien niet voldoende zekerheid aanwezig wordt geacht, dat voor opeenvolgende transacties krediet beschikbaar is, zal de partiële methode niet worden toegepast. Bovendien wijst de door J. L. Mey gestelde eis tot vorming van weerstandsvermogen in de vorm van actief-reserves er wel op, dat verder dient te worden gekeken dan de te financieren transacties.

De Lange is van oordeel, dat nimmer een verband kan worden gelegd tussen de onderscheiden soorten aangetrokken vermogen en bepaalde kapitaalgoederen, groepen van kapitaalgoederen of transacties. „Evenmin als een consument met meerdere bronnen van inkomen kan zeggen, uit welke inkomensbron hij de huishuur en uit welke inkomensbron hij de levensmiddelen betaalt, evenmin kan men ten aanzien van de financiering van een bedrijf stellen, dat bepaalde kapitaalgoederen of bepaalde transacties gefinancierd worden uit bepaalde vermogensbronnen" (blz 32). Deze opmerking van de schrijver houdt o.i. geen steek. Uiteraard zijn de financieringsmiddelen volkomen ,interchangeable" en kan nooit worden vastgesteld uit welke bron de middelen vloeien, waarmede bepaalde bestedingen worden verricht. Dit betekent echter niet, dat er geen verband gelegd zou kunnen worden tussen bepaalde financieringstransacties en bepaalde bestedingen. Sommige financieringstransacties (b.v. het leverancierskrediet) zijn zelfs onverbrekelijk met de besteding verbonden. Het is alleszins denkbaar dat een obligatielening wordt gesloten ter financiering van met name genoemde activa. In de Lange's opvatting zou men waarschijnlijk ook niet mogen spreken over een uitkering uit agio-reserve, omdat men niet weet of de uitgekeerde gelden inderdaad wel uit het destijds verkregen agio zijn betaald. $D$ it gaat o.i. te ver. 
Ook al kan men met de Lange instemmen, dat het aanleggen van reserveactiva een kostbaar middel is ter bestrijding van de onzekerheid behoeft dat nog geen reden te zijn tot verwerping van partiële financiering onder bepaalde omstandigheden. De keuze van deze methode zal veelal berusten op rentabiliteitsoverwegingen en het spreekt vanzelf dat de kosten, verbonden aan de aanhouding van reserve-activa zeker in het oordeel zullen worden betrokken.

De Lange meent, dat er een betere weg kan worden ingeslagen bij de bestrijding van de onzekerheid onder dynamische verhoudingen, nl. door bij de bepaling van de financieringsmethode rekening te houden met de mogelijkheid, dat onverwachte vermogensbehoeften kunnen optreden en de methode daarom zo te kiezen, dat zij te allen tijde gelegenheid tot verdere vermogensverwerving biedt (blz. 35). In feite betekent dit ook een zich richten op de versterking van het weerstandsvermogen en wel door verhoging van de kredietwaardigheid of - om een term van van Ketel te gebruiken - de kapitaalwaardigheid van de onderneming. Dat J. L. Mey deze methode niet over het hoofd heeft gezien, blijkt o.i. uit zijn proefschrift waar hij in hoofdstuk IV, par. 6 (blz. 68/69) spreekt over weerstandsvermogen en kredietwaardigheid. De Lange wekt de indruk, dat zijn visie op het financieringsvraagstuk zeer sterk afwijkt van de opvattingen van J. L. Mev. Naar dezerzijdse mening is die tegenstelling echter niet aanwezig. Wij zouden de Lange's visie op het financieringsvraagstuk liever willen zien als een verdere uitbouw van de theorie na de o.i. importante bijdrage, die J. L. Mey daartoe reeds had geleverd.

Het voorlopige karakter, dat de Lange in iedere financieringsmaatregel ziet, is ongetwijfeld een goede vondst. Dit moge vóór hem niet zo nadrukkelijk zijn uitgesproken, doch dat betekent niet dat anderen - w.o. J. L. Mey en Diepenhorst - elke financieringsmethode als definitief voor de onderneming zouden willen aanmerken.

\section{Dynamische theorie en financieringsbeleid}

De Lange is niet tevreden met de veronderstelling van dynamische verhoudingen bij de benadering van het financieringsvraagstuk, hij wenst ook na te gaan op welke wijze de waarden der gevraagde grootheden reageren op de veranderingen in de waarden der data (blz. 17). Hierbij maakt hij, in navolging van Tinbergen, onderscheid tussen statische en dvnamische theorie. Het bekende verschil tussen deze beide is, dat in de statica de aanpassing aan de gewijzigde data verondersteld wordt onmiddellijk en volledig tot stand te komen, waartegenover in de dynamica het tijdselement mede in de beschouwing wordt opgenomen. Tijdens het aanpassingsproces kunnen nieuwe veranderingen in de data optreden, de ontwikkeling zelve kan nieuwe situaties scheppen en het verschil in tempo waarmede de verschil lende economische grootheden zich aanpassen kan secundaire reacties oproepen. In de dynamica kan dan ook geen sprake zijn van een evenwichtstoestand.

De Lange wenst de dynamica te introduceren in de financieringstheorie. De aanpassing van de gevraagde grootheden aan wijzigingen in de data voltrekt zich niet automatisch. $Z_{i j}$ wordt bewerkstelligd door de ondernemingsleiding. Het optreden van veranderingen in de datumwaarden wordt minder bepaald door feitelijke gebeurtenissen dan door het inzicht van de bedrijfsleiding. Zelfs als een feitelijke verandering in de waarde van een gegeven grootheid zich voltrekt, zal het nog van het oordeel van de bedrijfsleiding afhangen of zij als zodanig zal worden aangemerkt en of zij 
aanleiding zal geven tot enige reactie met betrekking tot de gevraagde grootheden (blz. 18). De aanpassing aan de nieuwe situatie zal bovendien tijd vergen. Mogelijk worden tijdelijke aanpassingsmaatregelen getroffen en het is denkbaar, dat de aanvankelijk gedachte aanpassing nimmer wordt bereikt, omdat zich intussen nieuwe omstandigheden kunnen voordoen (blz. 18/19).

Met het bovenstaande zijn feitelijk de beleidselementen in de dynamische financieringstheorie aangegeven. Het beleid heeft niet alleen betrekking op het treffen van maatregelen op de grondslag van veranderde data, het zal tevens gericht moeten zijn op zodanige beinvloeding der data als voor het ondernemingsdoel wenselijk wordt geacht (blz. 45). Structurele noch conjuncturele veranderingen kunnen zonder meer op de data in het enkele bedrijf worden toegepast. Alles hangt ervan af hoe de bedrijfsleiding daarop heeft gereageerd en als veranderingen van langere of kortere duur heeft verwerkt. Het financieringsbeleid staat niet op zichzelf doch is onverbrekelijk met het algemene beleid verbonden. De waarden der data in het probleem van de financiering kunnen niet worden gekend, alvorens het ondernemingsbestuur vele andere beleidsproblemen heeft opgelost (blz. 46). De keuze van financieringsfiguren - zo menen wij de Lange te mogen interpreteren - is een beleidskwestie en wel een beleidskwestie die niet op zichzelf staat doch ingebed is in het algemene ondernemingsbeleid. Dit laatste is bepalend voor de waarden der data en het berust in hoofdzaak op verwachtingen, welke gekoesterd worden ten aanzien van de toekomstige bedrijfsontwikkeling. De keuze der financieringsfiguren wordt hierop gebaseerd, doch de onzekerheid brengt mede, dat de gekozen financiële structuur nooit als een definitieve kan worden gezien. Het beleid zal erop gericht moeten zijn de toegang tot de bronnen van vermogen open te houden. Hangende een bepaalde ontwikkeling zal vaak op een toekomstige verkrijgingsmogelijkheid moeten worden geanticipeerd.

De opvatting, dat de keuze van financieringsfiguren een kwestie van beleid is kan niet als nieuw worden aangemerkt. In het maandschrift Economie van januari 1957, hebben wij, in een artikel onder de titel ,.Financieringstheorie en financieringspraktijk" er reeds de aandacht op gevestigd, dat met name Diepenhorst en van der Velden de oplossing van het financieringsvraagstuk als een beleidszaak zien, waar de theorie buiten staat.1) $Z_{\mathrm{ij}}$ trekken daaruit de conclusie, dat er ook geen normen voor de financiering kunnen worden opgesteld. Het komt ons voor, dat ook wanneer men erkent, dat financiering een beleidszaak is, dit nog niet behoeft te betekenen. dat de theorie daar buiten moet blijven, dat m.a.w. het financieringsbeleid niet nader zou kunnen worden bestudeerd en dat op grond daarvan geen richtlijnen voor dit beleid zouden kunnen worden opgesteld. Deze gedachte ontwikkelden wij in onze voordracht voor de Tilburgse Academische Economische Kring op 13 april 19572 ) en het was verheugend enige tijd daarna de Lange's proefschrift te mogen ontvangen, waarin juist het financieringsbeleid nader wordt geanalyseerd en waarin getracht wordt om te komen tot de opstelling van grondslagen voor het financieringsbeleid (blz, 64). Dit financieringsbeleid vormt bij hem zelfs, zoals uit het voorafgaande moge zijn gebleken een integrerend bestanddeel van een dynamische financieringstheorie. Het algemene ondernemingsbeleid bepaalt de waarden van de data van het financieringsvraagstuk, zoals boven reeds werd opgemerkt. Voor het financieringsprobleem is het algemene bedrijfsbeleid daarom zelve een

1) T.a.p. blz. $143 / 144$.

2) Zie Maandschrift Economie, 21e jaargang, blz. 379 e.v. 
datum (blz.68). Het typische financieringsbeleid bestaat in ,het verkrijgen en behouden van toegang tot die delen van de vermogensmarkt, welke voor een doelmatige voorziening in de vermogensbehoefte van belang zijn, alsmede in het bevorderen van de vorming van eigen vermogen in de onderneming" (blz. 69).

Voor het voeren van dit beleid is de kennis en bestudering van de data een eerste vereiste. Eerst wanneer men de data volledig kent zal het financieringsvraagstuk oplosbaar zijn en zullen er duidelijke en concrete richtlijnen voor dit beleid kunnen worden uitgestippeld. Dit komt feitelijk hierop neer, dat men de objectieve marktsituatie van de onderneming zal moeten kennen en haar concrete doelstellingen vooraleer er van normen voor het beleid kan worden gesproken. ${ }^{3}$ )

In dit verband dient grote aandacht te worden besteed aan de financieringsbegroting. Daarin vindt men $\mathrm{nl}$. de kristallisatie van het algemene beleid, gebaseerd op de concrete marktsituatie en de verwachting, welke men omtrent de ontwikkeling daarvan heeft in de toekomst. $Z_{i j}$ verschaft inzicht in de verwachte ontwikkeling van de data. De Lange pleit voor de opstelling van meervoudige begrotingen met alternatieve mogelijkheden voor het bedrijfsbeleid om de onzekerheid tot uitdrukking te brengen (blz. 50). Bij de opstelling van een enkelvoudige begroting wordt uit de diverse mogelijkheden van ontwikkeling een bepaalde keuze gedaan. Dit geeft aan die ontwikkeling - zo meent de schrijver - een voorzienbaar karakter en ademt een statische geest.

Op het eerste gezicht lijkt dit plausibel. De Lange ziet hierbij echter o.i. wel over het hoofd, dat de onderneming op een gegeven moment een keuze zal moeten doen. $Z_{i j}$ zal er zeker goed aan doen voldoende ruimte te laten voor flexibele aanpassing, wanneer de realiteit van het plan afwijkt, doch daarbij mag niet worden vergeten, dat op grond van de gedane keuze, op basis van de meest waarschijnlijk geachte ontwikkeling, bepaalde investeringen zullen worden gedaan, waar men zonder meer niet vanaf kan. Heeft men voorts reeds financieringsmiddelen opgenomen van derden, dan zit men als regel aan een bepaald aflossingsschema vast, dat zich niet meer voor flexibele aanpassing leent. De Lange wijst er zelf op, dat de keuze van een financieringsmethode voor elk volgend financieringsprobleem een groep van data on wrikbaar vastlegt (blz. 56). Wanneer men mèt de Lange erkent, dat somtijds meerdere ontwikkelingen denkbaar zijn, neemt dit niet weg, dat men zijn beleid toch op de meest waarschijnlijke ontwikkeling zal moeten richten. Tegenover afwijkingen van de geplande ontwikkeling. waarmede moet worden gerekend, zal o.i. weerstandsvermogen aanwezig moeten zijn, b.v. doordat gezorgd wordt, dat de toegang tot de kapitaalmarkt open blijft.

Voor een doelmatig financieringsbeleid acht de Lange van grote betekenis, dat het waarnemingsapparaat van het bedrijf zodanig wordt uitgerust, dat de perioden waarin de ontwikkelingen der datumwaarden kunnen worden overzien, voor alle data van ongeveer gelijke duur kunnen zijn. De aldus opgestelde financieringsbegroting zal een beeld kunnen geven van de ontwikkelingen in de kapitaals-en in de vermogenssructuur, zoals deze met meer of minder waarschijnlijkheid mogen worden verwacht (blz. $62 / 63$ ). Men zal kunnen komen tot voorgecalculeerde balansen en resultatenrekeningen (uitgangssituatie plus begroting). Dit toekomstbeeld heeft in de dynamische theorie niet het karakter van ,een doel, waarnaar gestreefd

3) Zie Maandschrift Economie, 21e jaargang, blz. 144. 
moet worden", zij geeft slechts de neerslag van verwachte ontwikkelingen.

N.o.m. zal dit toekomstbeeld zelve mede een beslissende rol spelen in de opstelling van het plan. Het is nl. zeer wel denkbaar dat een eerste proeve van financieringsplan wijziging behoeft op grond van het feit, dat de effectuering daarvan tot een ongewenste financiële structuur zal leiden. Voorts zal men o.i. bij afwijkingen tussen realisatie en prognose telkens de effecten op de toekomstige structuur willen bezien en mede op grond daarvan al of niet wijzigingen in de financieringsmethode wensen aan te brengen, voorzover dit in verband met reeds getroffen maatregelen nog mogelijk is. Dit impliceert inderdaad niet het streven naar een bepaalde structuur als absoluut doel. De vermogensstructuur alléen is niet normatief, doch ze is wel een medebepalend element bij de besluitvorming op het terrein van het financieringsbeleid. Wij vermogen niet in te zien dat de in dit systeem ingebouwde flexibiliteit op enigerlei wijze zou kunnen duiden op statische theorie.

Terecht merkt de Lange op, dat de begroting toch ook weer niets anders kan zijn dan de cijfermatige weergave van de financieringsmethode (blz. 51) en dat alleen de financieringstheorie de financieringsmethode zelf zal kunnen aangeven. De begroting verschaft m.a.w. de data voor het beleid, de richtlijnen voor het beleid zelf zijn daarmede nog niet gegeven.

Als algemene beginselen voor het financieringsbeleid formuleert de Lange nu:

le. de zorg verzekerd te $z$ ijn van beschikbaarheid van het vermogen, zodra en zolang het nodig is;

2e. het streven naar de methode met de laagste kosten (blz. 57).

We herkennen hier het liquiditeitsbeginsel en het kostenbeginsel, waaromtrent in de leer van de financiering nogal een en ander te doen is geweest. Niemand zal de Lange tegenspreken, dat aan beide aspecten te allen tijde aandacht moet worden besteed. Het valt op, dat hij het eerste beginsel niet formuleert als de zorg voor de overeenstemming van de termijnen van vermogensbehoefte en vermogensbeschikbaarheid, zoals Polak dit deed. Bij de Lange heeft het een ruimere inhoud. Niet alleen de termijn der vermogensbeschikbaarheid is nl. van belang, maar ook de overige voorwaarden van beschikbaarstelling zullen zodanig moeten zijn ,,dat daaruit geen ontijdige teruggave van het vermogen, noch een belemmering van de aantrekking van meer vermogen kan voortvloeien" (blz. 57).

In de literatuur werd het vraagstuk der vermogensbeschikbaarheid als regel onder statische verhoudingen gesteld, doordat uitgegaan werd van een onveranderlijk gedacht circulatieproces en een kapitaalmarkt, waar te allen tijde een rijk geschakeerd patroon van financieringsfiguren ter vrije keuze van de ondernemer beschikbaar zou zijn. De Lange realiseert zich echter dat van een onveranderlijk circulatieproces geen sprake kan zijn en dat juist daarom het oordeel van de bedrijfsleiding voor de te verwachten ontwikkelingen en de mogeliikheden van heinvloeding der data van zo groot belang moet worden geacht. Elke aantrekking van tijdelijk vermogen vereist b.v. inzicht omtrent de bronnen, waaruit zowel rente- als aflossingsverplichtingen kunnen worden nagekomen. Zonder dit toekomstbeeld acht de Lanqe financiering met tijdelijk vermogen een stap in het duister (blz. 60 ). Wij vragen ons af of niet reeds alle schrijvers, die open oog hebben gehad voor het onzekerheidselement dit zo hebben gezien. De visie van de Lange correspondeert als wij het goed zien met die van van Berkum.

$\mathrm{m}$ a b blz. 48 
die de volgende algemene norm van financieringsbeleid definieerde: „Hoe groter het risico en de conjunctuurgevoeligheid van de kapitaalgoederen zijn, welke aan de actiefzijde van de balans paraisseren, hoe groter volgens dit beginsel aan de passiefzijde het bestanddeel risicodragend kapitaal zal moeten wezen." 4 ) Ook hieruit valt af te leiden, dat de nadruk gelegd dient te worden op de vorming van een oordeel omtrent de toekomstige ontwikkelingen.

In feite blijkt de Lange hier ook niet zover af te staan van J. L. Mey, wanneer hij zegt: ,Evenzeer zal het bedrijf moeten zorgdragen, dat het in tijden van verlies, waarin een deel van het beschikbare vermogen verloren gaat en nieuw vermogen niet verworven kan worden, over voldoende vermogen blijft beschikken; daartoe kan het overwegen reservevermogen aan te houden" (blz. 58, Wij menen nl. te mogen aannemen, dat dit reservevermogen dan ook in zodanige vorm aanwezig moet zijn, dat het alsdan actief kan worden aangewend.

Ook ten aanzien van het kostenbeginsel geldt dat dit in de literatuur veelal onder statische verhoudingen werd gesteld. De Lange echter leert, dat de keuze van de financieringsmethode met de laagste kosten geenszins alleen een kwestie van vergelijking van huidige prijzen is. Zowel met het oog op de bepaling van het juiste moment van verwerving als op een mogelijke vervanging van vermogen ter bereiking van kostenvoordelen zijn de toekomstige ontwikkelingen van de vermogensprijzen van betekenis (blz. $60)$. Dit houdt derhalve in, dat het waarnemingsapparaat van de onderneming zich ook omtrent de te verwachten ontwikkelingen op de kapitaalmarkt zal hebben te oriënteren. Men zal zich hierbij hebben te realiseren. dat de bereidheid van aanbieders van vermogen om dit aan het bedrijf ter beschikking te stellen in hoge mate afhankelijk is, voorzover het tijdelijk vermogen betreft, van de mate van zekerheid, dat rente en aflossing kunnen worden voldaan en voorzover het permanent vermogen betreft, dat regelmatig in uitzicht gestelde dividenden worden gedeclareerd. De structurele en conjuncturele ontwikkelingen in de winstgevendheid van het bedrijf spelen een belangrijke rol bij de vaststelling van de voorwaarden, waarop het vermogen kan worden verworven. De beinvloeding van deze ontwikkelingen zal een belangrijk onderdeel van het beleid moeten uitmaken (blz. 70).

Met betrekking tot de vermogensbeschikbaarheid blijkt de bestudering van de data eveneens van groot belang te zijn voor de oplossing van het financieringsvraagstuk. Van Ravenstijn had hiervoor in zijn artikel „Over de betekenis van het Financieringsplan als centraal studie-object van de leer der financiering" (N.V. Mei 1952) reeds de aandacht gevraagd.

In het voorafgaande hebben wij getracht duidelijk te maken, dat de Lange het liquiditeits- en kostenbeginsel als algemene richtlijnen van het financieringsbeleid beslist anders hanteert dan in de statische theorie gebruikelijk is. Met deze algemene richtlijnen kan hij echter het te voeren beleid onder gegeven omstandigheden niet volledig uitstippelen. Daarvoor moeten de gedragingen van alle data in concreto worden onderzocht.

Een volledig onderzoek naar de gedragingen van alle data onder de invloed van structurele en conjuncturele invloeden kon de Lange in zijn boek uiteraard niet ter hand nemen. Hij heeft zich daarom beperkt tot een nader onderzoek naar de behoefte van en voorziening met permanent vermogen

4) Zie P. P. van Berkum: De kapitalisatie der naamloze vennootschap. in De Naamloze Vennootschap, februari/maart 1953. 
bij Nederlandse Naamloze Vennootschappen onder de huidige verhoudingen op de vermogensmarkt in het bijzonder en bij de huidige maatschappelijke en economische structuur in het algemeen (blz. 184). Hieraan zijn de hoofdstukken V tot en met VIl gewijd, welke meer dan de helft van het werk in beslag nemen.

\section{Behoefte aan permanent vermogen en de voorziening daarin}

In deze hoofdstukken wordt de in het voorafgaande ontwikkelde theorie feitelijk toegepast op het vraagstuk van de behoefte aan permanente financieringsmiddelen en de voorziening daarin. Nieuwe gezichtspunten, van essentieel belang, worden daarin aan de reeds gegeven beschouwingen niet toegevoegd. Wel vinden we hier de meer gedetailleerde bespiegelingen, waarop wij sub. 1. doelden. Wij zullen daarop niet ingaan, hoewel vele interessante facetten van het vraagstuk onder de loep worden genomen. Dit zou echter, zoals in de inleiding van dit artikel reeds werd opgemerkt, te ver voeren.

Wij zullen trachten in kort bestek enkele hoofdzaken uit de betreffende hoofdstukken weer te geven, waaruit duidelijk de toepassing der eerder gegeven analyse blijkt.

Het algemene bedrijfsbeleid komt tot uitdrukking in de factoren, die de kapitaalsgrootte beheersen (de functionele plaats en de produktiemethode van het bedrijf, de produktieomvang, de prijsverhoudingen van produktiemiddelen en produkten). Naarmate het beleid ten aanzien van deze faktoren wordt herzien zal de kapitaalsgrootte een andere ontwikkeling vertonen en zal daarmede de permanente vermogensbehoefte zich wijzigen. Zolang de diversiteit in de tijdstippen en bedragen der heraanschaffingen nog gering is, zullen de fluctuaties in de kapitaalsgrootte vrij aanzienlijk kunnen zijn. Neemt de diversiteit echter toe dan gaat de behoefte aan vermogen een gelijkmatig verloop vertonen en krijgt deze een meer permanent karakter. Men kan spreken van een bepaalde kapitaalstructuur. Vergroting nu van de produktieomvang of rationalisatie van de produktiemethode zullen wijziging brengen in deze structuur, doch de overgang zal een zekere tijd vergen en bovendien kan zij slechts voor een beperkte periode worden voorzien. D e daaromtrent gekoesterde verwachtingen strekken zich - aldus de Lange - niet tot de gehele bestaansduur van het bedrijf uit. Wat er na de periode, waarop de verwachtingen zijn gebaseerd, zal geschieden, valt niet te bekijken en men gaat dus feitelijk uit van het bereiken van een soort evenwichtsphase aan het einde van de ontwikkelingsprognosis. Het spreekt echter vanzelf, dat daarna weer nieuwe ontwikkelingen kunnen optreden en dit leidt tot de conclusie, dat het oordeel omtrent de grootte van de permanente vermogensbehoefte in de tijd gezien altijd slechts een voorlopig karakter kan dragen en de voorziening daarin zal door dit voorlopige karakter worden beheerst. Men zal hiervoor geen vaste normen kunnen opstellen. De keuze der financieringsmethode is een zaak van beleid. Als belangrijke beleidsaangelegenheden voortvloeiend uit het onzekerheidselement bij de bepaling der permanente vermogensbehoefte ziet de Lange: a. het open houden van de toegang tot de aandelenmarkt; $b$. het vraagstuk van de reservevorming en $c$. de voorfinanciering met tijdelijk vermogen.

Hoofdstuk VI behandelt de verwerving van permanent vermogen en wel met name bij de open naamloze vennootschap. Gezien het feit, dat de ontwikkelingen in de behoefte aan permanent vermogen onvoorzienbaar zijn, zal de onderneming haar beleid moeten richten op het openhouden 
van de mogelijkheden tot opneming van vermogen op de kapitaalmarkt. Dit beleid zal mede afhankelijk zijn van de voor de prijsvorming van het aandeel bepalende faktoren en dit zijn voornamelijk de dividendverwachtingen en het verlangde rendement. Het zal gericht moeten zijn op het verwekken van zo hoog mogelijke dividendverwachtingen en het genoegen nemen met een zo laag mogelijk rendement. De bij een emissie gekoesterde dividendverwachtingen zullen worden gebaseerd op de in het verleden gevoerde dividendpolitiek, waaruit tevens zal moeten blijken of verwekte dividendverwachtingen in het verleden ook werden waar gemaakt.

De consequentie uit het voorafgaande is, dat een grote mate van stabiliteit in de dividend- en reserveringspolitiek vereist is om de toegang tot de kapitaalmarkt open te houden. Weet men in de permanente vermogensbehoefte zolang mogelijk door reservevorming te voorzien en zal men daardoor slechts met geringe frequentie een beroep op de vermogensmarkt moeten doen dan zal men zich grotere vrijheden ten aanzien van dividend- en reserveringspolitiek kunnen veroorloven.

Het openhouden van de toegang tot de kapitaalmarkt vormt de kern van de Lange's betoog in dit hoofdstuk.

In hoofdstuk VII behandelt de Lange de voorfinanciering met tijdelijk vermogen. Er kunnen redenen zijn voor de onderneming om ter voorziening in een permanente vermogensbehoefte een voorlopige voorziening te treffen door tijdelijke financieringsmiddelen an te trekken. De Lange onderscheidt hierbij drie gevallen naar de redenen waarom men tot deze financieringsmethode zijn toevlucht neemt. Dit zal nl. het geval kunnen zijn:

1. wanneer de omvang der behoefte nog niet te overzien valt doordat het groeiproces nog in volle gang is;

2. wanneer de aantrekking van het benodigde permanente vermogen een zekere periode van voorbereiding eist (overbruggings- of anticipatiekredieten):

3. uit rentabiliteitsoverwegingen.

De voorfinanciering mag alleen dan toegepast worden, wanneer er een redelijke verwachting bestaat, dat de onderneming te zijner tijd over het benodigde permanente vermogen zal kunnen beschikken.

In de eerste twee gevallen kan een keuze voor de ondernemingsleiding nauwelijks worden gesproken. De omstandigheden nopen hier tot het aantrekken van tijdelijke middelen. In het derde geval gaat het feitelijk om een waarlijk vrije keuze tussen financiering met leningen dan wel met aandelen.

Men kan in het laatste geval toch van voorfinanciering spreken, omdat uitdrukkelijk gesteld is, dat het hier om voorziening in permanente vermogensbehoeften gaat. Dit betekent, dat na verloop van tijd de aangetrokken tijdelijke middelen door permanente middelen zullen moeten worden vervangen, welke verkregen kunnen worden uit winstinhouding dan wel door uitgifte van aandelen. Het is bijzonder verheugend, dat de Lange ook de voorfinanciering in anticipatie op te verwachten winsten, welke kunnen worden ingehouden, in zijn beschouwingen heeft opgenomen. In ons eerdergenoemde januari-artikel in Maandschrift Economie hebben wij er destijds reeds op gewezen, dat in de theorie aan het gebruik van vreemde middelen in anticipatie op te verwachte reserveringsmogelijkheden onvoldoende aandacht wordt geschonken. De Lange wijst erop, dat bij het overwegen van deze financieringsmethode men mede de vraag aan de orde zal moeten stellen in welke financiële positie het bedrijf dreigt te geraken, indien ach- 
teraf de winsten onvoldoende zouden blijken om de middelen voor de aflossing en wellicht ook voor de rentebetaling op te leveren (blz. 155). Dit betekent 0.1 . weer een onderzoek naar het weerstandsvermogen. Mocht dit weerstandsvermogen in voldoende mate aanwezig blijken te zijn dan kan er tegen de bedoelde voorfinanciering weinig worden ingebracht.

\section{Slotopmerking}

Wij zijn ons bewust door het achterwege laten van beschouwingen over de Lange's gedetailleerde analyse van het financieringsbeleid met betrekking tot de voorziening in permanente vermogensbehoeften een onvolmaakt beeld gegeven te hebben van zijn belangwekkende studie. De reden van de beperking welke wij ons hier meenden te moeten opleggen, werd reeds gegeven.

Nadrukkelijk moge echter worden vastgesteld, dat wij deze analyse zeer waardevol achten. De schrijver heeft, naar onze mening, met de gegeven beschouwingen een bijdrage geleverd tot de leer van de financiering, welke niet alleen uit theoretisch oogpunt, doch ook voor de praktijk van groot belang kan worden geacht. Dit laatste kon worden bereikt door de realistische visie van de schrijver op het financieringsvraagstuk. Ten aanzien van het probleem der voorziening in permanente vermogensbehoeften onder bepaalde omstandigheden heeft hij duidelijk richtlijnen voor het beleid uitgestippeld. Dit moet als een bijzondere verdienste worden aangemerkt. 